\title{
Common fixed points of two pairs of mappings satisfying (E.A)-property in partial metric spaces
}

\author{
Talat Nazir ${ }^{1,2^{*}}$ and Mujahid Abbas ${ }^{3,4}$
}

*Correspondence: talat@ciit.net.pk 1 Department of Mathematics, COMSATS Institute of Information Technology, Abbottabad, 22060, Pakistan

${ }^{2}$ Department of Mathematics and Computer Sciences, Technical University Eindhoven, Eindhoven, 5612, The Netherlands Full list of author information is available at the end of the article

\begin{abstract}
In this paper, we present common coincidence and common fixed point results for two pairs of mappings that satisfy the (E.A)-property in the setup of partial metric spaces. Some examples are given to validate the concepts and results presented herein. Well-posedness of the common fixed point problem is also studied.
\end{abstract} MSC: $47 \mathrm{H} 10 ; 54 \mathrm{H} 25 ; 54 \mathrm{E} 50$

Keywords: compatible maps; (E.A)-property; coincidence point; common fixed point; well-posedness; partial metric space

\section{Introduction and preliminaries}

Over the last 50 years or so the theory of fixed points has been revealed as a very powerful and important tool in the study of nonlinear phenomena. In particular, fixed point techniques have been applied in such diverse fields as biology, chemistry, economics, engineering, game theory, and physics. In the past years, the extension of metric fixed point theory to generalized structures such as cone metrics, partial metric spaces and quasimetric spaces has received much attention (see, for instance, [1-6] and the references therein). A partial metric space is a generalized metric space in which each object does not necessarily has to have a zero distance from itself [7]. One motivation for introducing the concept of a partial metric was to obtain appropriate mathematical models in the theory of computation and, in particular, to give a modified version of the Banach contraction principle, more suitable in this context $[7,8]$. Subsequently, several authors have studied the problem of existence and uniqueness of a fixed point for mappings satisfying different contractive conditions (see, e.g., [9-19]).

Recently, it was shown that, in some cases, fixed point results in partial metric spaces can be obtained directly from their induced metric counterparts [20-22]. However, some important conclusions in the application of partial metrics to information sciences cannot be obtained in this way. For example, if $x$ is a fixed point of a map $f$, then, by using the method from [20], we cannot conclude that $p(f x, f x)=0=p(x, x)$. For further details we refer the reader to [23] and [24].

The aim of this paper is to study the existence of a common fixed point for two pairs of mappings which satisfy the (E.A)-property in the framework of partial metric spaces. Our results do not require the maps to be commuting or continuous. We will also give 
an example to show that the conclusion of our results cannot be derived by employing an induced metric.

In the sequel, $\mathbb{R}, \mathbb{R}^{+}$, and $\mathbb{N}$ denote the set of all real numbers, the set of all nonnegative real numbers and the set of all positive integers, respectively. The usual order on $\mathbb{R}$ will be indistinctly denoted by $\leq$ or by $\geq$.

Consistent with [7] and [25], the following definitions and results will be needed in the sequel.

Definition 1.1 Let $X$ be a nonempty set. A function $p: X \times X \rightarrow \mathbb{R}^{+}$is said to be a partial metric on $X$ if, for any $x, y, z \in X$, the following conditions hold:

$\left(\mathrm{P}_{1}\right) p(x, x)=p(y, y)=p(x, y)$ if and only if $x=y$;

$\left(\mathrm{P}_{2}\right) p(x, x) \leq p(x, y)$

$\left(\mathrm{P}_{3}\right) p(x, y)=p(y, x)$;

$\left(\mathrm{P}_{4}\right) p(x, z) \leq p(x, y)+p(y, z)-p(y, y)$.

The pair $(X, p)$ is then called a partial metric space.

If $p(x, y)=0$, then $\left(\mathrm{P}_{1}\right)-\left(\mathrm{P}_{3}\right)$ imply that $x=y$, but the converse does not always hold.

A trivial example of a partial metric space is the pair $\left(\mathbb{R}^{+}, p\right)$, where $p: \mathbb{R}^{+} \times \mathbb{R}^{+} \rightarrow \mathbb{R}^{+}$is defined by $p(x, y)=\max \{x, y\}$.

Example 1.2 [7] If $X=\{[a, b]: a, b \in \mathbb{R}, a \leq b\}$, then $p([a, b],[c, d])=\max \{b, d\}-\min \{a, c\}$ defines a partial metric $p$ on $X$.

For more examples of partial metric spaces, we refer the reader to [14, 16, 17, 25-28].

Each partial metric $p$ on $X$ generates a $T_{0}$ topology $\tau_{p}$ on $X$ which has as a base the family open $p$-balls $\left\{B_{p}(x, \varepsilon): x \in X, \varepsilon>0\right\}$, where $B_{p}(x, \varepsilon)=\{y \in X: p(x, y)<p(x, x)+\varepsilon\}$, for all $x \in X$ and $\varepsilon>0$.

Definition 1.3 [7] A sequence $\left\{x_{n}\right\}$ in a partial metric space $(X, p)$ is said to be a Cauchy sequence if $\lim _{n, m \rightarrow \infty} p\left(x_{n}, x_{m}\right)$ exists and is finite.

It is well known that (see [7, p.187]) a sequence $\left\{x_{n}\right\}$ in a partial metric space $(X, p)$ converges to a point $x \in X$, with respect to $\tau_{p}$, if and only if $p(x, x)=\lim _{n \rightarrow \infty} p\left(x, x_{n}\right)$.

If $p$ is a partial metric on $X$ then the function $p^{S}: X \times X \rightarrow \mathbb{R}^{+}$, given by $p^{S}(x, y)=$ $2 p(x, y)-p(x, x)-p(y, y)$, defines a metric on $X$.

A sequence $\left\{x_{n}\right\}$ converges in $\left(X, p^{S}\right)$ to a point $x \in X$ if and only if

$$
\lim _{n, m \rightarrow \infty} p\left(x_{n}, x_{m}\right)=\lim _{n \rightarrow \infty} p\left(x_{n}, x\right)=p(x, x) .
$$

This will be denoted as $x_{n} \rightarrow x$ as $n \rightarrow \infty$ or $\lim _{n \rightarrow \infty} x_{n}=x$. Clearly, the limit of a sequence in a partial metric space need not be unique. Moreover, contrary to the case of an ordinary metric $d$, a partial metric $p$ need not be continuous, in the sense that $x_{n} \rightarrow x$ and $y_{n} \rightarrow y$ as $n \rightarrow \infty$ does not imply that $p\left(x_{n}, y_{n}\right) \rightarrow p(x, y)$ as $n \rightarrow \infty$.

A partial metric space $(X, p)$ is said to be complete if every Cauchy sequence $\left\{x_{n}\right\}$ in $X$ converges, with respect to $\tau_{p}$, to a point $x \in X$ such that $\lim _{n \rightarrow \infty} p\left(x, x_{n}\right)=p(x, x)$. In this case we say that the partial metric $p$ is complete. 
The following example shows that a convergent sequence in a partial metric space may not be Cauchy. In particular, it shows that the limit of a convergent sequence is not unique.

Example 1.4 [7] Let $p: \mathbb{R}^{+} \times \mathbb{R}^{+} \rightarrow \mathbb{R}^{+}$be a partial metric defined as $p(x, y)=\max \{x, y\}$.

Define a sequence $\left\{x_{n}\right\}$ as

$$
x_{n}= \begin{cases}0 & \text { if } n=2 k \\ 1 & \text { if } n=2 k+1 .\end{cases}
$$

Then $\left\{x_{n}\right\}$ is a convergent sequence but $\lim _{n, m \rightarrow \infty} p\left(x_{n}, x_{m}\right)$ does not exist.

Lemma 1.5 [25] Let $(X, p)$ be a partial metric space.

(a) A sequence $\left\{x_{n}\right\}$ in $X$ is a Cauchy sequence in $(X, p)$ if and only if it is a Cauchy sequence in the metric space $\left(X, p^{S}\right)$.

(b) A partial metric space $(X, p)$ is complete if and only if the metric space $\left(X, p^{S}\right)$ is complete.

If $f x=g x$ for some $x$ in $X$, then $x$ is called the coincidence point of $f$ and $g$. Furthermore, if the mappings commute at each coincidence point, then such mappings are called weakly compatible [29].

Sessa [30] introduced the notion of the weak commutativity of mappings in metric spaces.

Definition 1.6 Let $X$ be a partial metric space. Mappings $f, g: X \rightarrow X$ are called (i) compatible if, whenever a sequence $\left\{x_{n}\right\}$ in $X$ is such that $\left\{x_{n}\right\}$ and $\left\{g x_{n}\right\}$ are convergent to some $t \in X$, then $\lim _{n \rightarrow \infty} p\left(f g x_{n}, g f x_{n}\right)=p(t, t)$, and (ii) noncompatible if there exists at least one sequence $\left\{x_{n}\right\}$ in $X$ such that $\left\{f x_{n}\right\}$ and $\left\{g x_{n}\right\}$ are convergent to some $t \in X$, but $\lim _{n \rightarrow \infty} p\left(f g x_{n}, g f x_{n}\right)$ does not exist.

In 2002, Aamri and Moutaawakil [31] introduced the (E.A)-property and obtained common fixed points for two mappings. Recently, Babu and Negash [32] employed this concept to obtain some new common fixed point results (see also [33] and [34]).

Definition 1.7 Let $X$ be a partial metric space. Selfmaps $f$ and $g$ on $X$ are said to satisfy the (E.A)-property if there exists a sequence $\left\{x_{n}\right\}$ in $X$ such that $\left\{f x_{n}\right\}$ and $\left\{g x_{n}\right\}$ are convergent to some $t \in X$ and $p(t, t)=0$.

Example 1.8 Let $X=[0,4]$ be a partial metric space with

$$
p(x, y)= \begin{cases}|x-y| & \text { if } x, y \in[0,2] \\ \max \{x, y\} & \text { otherwise. }\end{cases}
$$

Let $f, g: X \rightarrow X$ be defined by

$$
f x= \begin{cases}2-x, & x \in[0,1], \\ \frac{2-x}{2}, & x \in(1,2], \\ 0, & x \in(2,4]\end{cases}
$$


and

$$
g x= \begin{cases}\frac{3-x}{2}, & x \in[0,1] \\ \frac{x}{2}, & x \in(1,4]\end{cases}
$$

For a decreasing sequence $\left\{x_{n}\right\}$ in $X$ such that $x_{n} \rightarrow 1, g x_{n} \rightarrow \frac{1}{2}, f x_{n} \rightarrow \frac{1}{2}, g f x_{n}=\frac{4+x_{n}}{4} \rightarrow \frac{5}{4}$ and $f g x_{n}=\frac{4-x_{n}}{2} \rightarrow \frac{3}{2}$. So $f$ and $g$ are noncompatible. Note that there exists a sequence $\left\{x_{n}\right\}$ in $X$ such that $\lim _{n \rightarrow \infty} f x_{n}=\lim _{n \rightarrow \infty} g x_{n}=1 \in X$. Take $x_{n}=1$ for each $n \in \mathbb{N}$. Hence $f$ and $g$ satisfy the (E.A)-property.

Let $f, g, S, T: X \rightarrow X$ be mappings. In our results, we assume that for every sequence $\left\{y_{n}\right\}$ in $X$, one of the following conditions holds:

(a) $\left\{g y_{n}\right\}$ is bounded in the case $(f, S)$ satisfies the (E.A)-property,

(b) $\left\{f y_{n}\right\}$ is bounded in the case $(g, T)$ satisfies (E.A)-property.

The following is an example where above assumption does not hold.

Example 1.9 Let $X=\mathbb{R}^{+}$be a partial metric space with $p(x, y)=\max \{x, y\}$ and $f, g, S, T$ : $X \rightarrow X$ be mappings defined by

$$
\begin{array}{ll}
f(x)=0, & g(x)=\frac{1+x}{2}, \\
S(x)=\frac{x}{2}, & T(x)= \begin{cases}0 & \text { if } x=0, \\
\frac{1}{4} & \text { otherwise. }\end{cases}
\end{array}
$$

Note that we have $f X \subseteq T X$ and $g X \subseteq S X$ with only the pair $(f, S)$ satisfying the (E.A)property. If $y_{n}=n$, then the sequence $\left\{g y_{n}\right\}$ is unbounded. Also note that the pairs $(f, S)$ and $(g, T)$ are weakly compatible. Here $f, g, S$ and $T$ do not have a common fixed point.

Definition 1.10 The control functions $\psi$ and $\phi$ are defined as

(a) $\psi, \phi:[0, \infty) \rightarrow[0, \infty)$ are functions, where $\psi$ is a continuous nondecreasing and $\phi$ is a lower semicontinuous with $\psi(t)=\phi(t)=0$ if and only if $t=0$,

(b) $\psi$ and $\phi$ satisfy

$$
\psi(t)+\phi(s) \leq \psi(s)
$$

for all $s, t \in[0, \infty)$ with $t \leq s$.

\section{Common fixed point theorems}

In this section some common fixed point results for two pairs of mappings satisfying certain contractive conditions in the framework of a partial metric space, are obtained. We start with the following result.

Theorem 2.1 Let $X$ be a partial metric space and $f, g, S, T: X \rightarrow X$ be mappings with $f X \subseteq T X$ and $g X \subseteq S X$ such that

$$
\psi(p(f x, g y)) \leq \psi(M(x, y))-\phi(M(x, y))
$$


is satisfied for all $x, y \in X$, where $\psi$ and $\phi$ are control functions and

$$
M(x, y)=\max \{p(S x, T y), p(f x, S x), p(T y, g y),[p(f x, T y)+p(S x, g y)] / 2\} .
$$

Suppose that one of the pairs $(f, S)$ and $(g, T)$ satisfies the (E.A)-property, and that one of the subspaces $f(X), g(X), S(X), T(X)$ is closed in $X$. If, for every sequence $\left\{y_{n}\right\}$ in $X$, one of the following conditions holds:

(a) $\left\{g y_{n}\right\}$ is bounded in the case $(f, S)$ satisfies the (E.A)-property, or

(b) $\left\{y_{n}\right\}$ is bounded in the case $(g, T)$ satisfies the (E.A)-property,

then the pairs $(f, S)$ and $(g, T)$ have a common point of coincidence in $X$. Moreover, if the pairs $(f, S)$ and $(g, T)$ are weakly compatible, then $f, g, S$ and $T$ have a unique common fixed point.

Proof If the pair $(f, S)$ satisfies the (E.A)-property, then there exists a sequence $\left\{x_{n}\right\}$ in $X$ satisfying $\lim _{n \rightarrow \infty} f x_{n}=\lim _{n \rightarrow \infty} S x_{n}=q$ for some $q \in X$. As $f X \subseteq T X$, there exists a sequence $\left\{y_{n}\right\}$ in $X$ such that $f x_{n}=T y_{n}$. As $\left\{g y_{n}\right\}$ is bounded, $\lim _{\sup _{n \rightarrow \infty}} p\left(f x_{n}, g y_{n}\right)$ and $\limsup _{n \rightarrow \infty} p\left(S x_{n}, g y_{n}\right)$ are finite numbers. Note that

$$
\left|p\left(f x_{n}, g y_{n}\right)-p\left(S x_{n}, g y_{n}\right)\right| \leq p\left(f x_{n}, S x_{n}\right) .
$$

Since $p\left(f x_{n}, S x_{n}\right) \rightarrow 0$ as $n \rightarrow \infty, \limsup _{n \rightarrow \infty} p\left(f x_{n}, g y_{n}\right)=\lim _{\sup _{n \rightarrow \infty}} p\left(S x_{n}, g y_{n}\right)$. Indeed, using the fact that $\limsup _{n \rightarrow \infty} p\left(f x_{n}, g y_{n}\right)=\lim _{\sup _{n \rightarrow \infty}} p\left(S x_{n}, g y_{n}\right)=l \geq 0$, we obtain subsequences $\left\{x_{n_{k}}\right\}$ and $\left\{y_{n_{k}}\right\}$ such that $p\left(S x_{n_{k}}, g y_{n_{k}}\right)$ and $p\left(f x_{n_{k}}, g y_{n_{k}}\right)$ are convergent to $l$. Assume that $l>0$. Replacing $x$ by $x_{n_{k}}$ and $y$ by $y_{n_{k}}$ in (2.1A), we have

$$
\begin{aligned}
M\left(x_{n_{k}}, y_{n_{k}}\right)= & \max \left\{p\left(S x_{n_{k}}, f x_{n_{k}}\right), p\left(f x_{n_{k}}, S x_{n_{k}}\right), p\left(f x_{n_{k}}, g y_{n_{k}}\right),\right. \\
& {\left.\left[p\left(f x_{n_{k}}, f x_{n_{k}}\right)+p\left(S x_{n_{k}}, g y_{n_{k}}\right)\right] / 2\right\}, }
\end{aligned}
$$

which, on taking the limit as $k \rightarrow \infty$, implies that

$$
\lim _{n \rightarrow \infty} M\left(x_{n_{k}}, y_{n_{k}}\right)=\max \{p(q, q), p(q, q), l, l / 2\}=l .
$$

From (2.1) we obtain

$$
\psi\left(p\left(f x_{n_{k}}, g y_{n_{k}}\right)\right) \leq \psi\left(M\left(x_{n_{k}}, y_{n_{k}}\right)\right)-\phi\left(M\left(x_{n_{k}}, y_{n_{k}}\right)\right)
$$

which, on taking the upper limit of both sides, gives

$$
\psi(l) \leq \psi(l)-\phi(l)<\psi(l),
$$

a contradiction. Therefore $l=0$. Hence $\lim _{n \rightarrow \infty} p\left(f x_{n}, g y_{n}\right)=\lim _{n \rightarrow \infty} p\left(S x_{n}, g y_{n}\right)=0$ and so $\lim _{n \rightarrow \infty} g y_{n}=q$.

If $T(X)$ is a closed subspace of $X$, then there exists an $r$ in $X$ such that $q=\operatorname{Tr}$. From (2.1) we have

$$
\psi\left(p\left(f x_{n}, g r\right)\right) \leq \psi\left(M\left(x_{n}, r\right)\right)-\phi\left(M\left(x_{n}, r\right)\right),
$$


where

$$
\begin{aligned}
M\left(x_{n}, r\right) & =\max \left\{p\left(S x_{n}, T r\right), p\left(f x_{n}, S x_{n}\right), p(\operatorname{Tr}, g r),\left[p\left(f x_{n}, \operatorname{Tr}\right)+p\left(S x_{n}, g r\right)\right] / 2\right\} \\
& =\max \left\{p\left(S x_{n}, q\right), p\left(f x_{n}, S x_{n}\right), p(q, g r),\left[p\left(f x_{n}, q\right)+p\left(S x_{n}, g r\right)\right] / 2\right\} .
\end{aligned}
$$

Using $\left(\mathrm{P}_{2}\right)$, we obtain

$$
\begin{aligned}
\limsup _{n \rightarrow \infty} M\left(x_{n}, r\right) & =\max \{p(q, q), p(q, q), p(q, g r),[p(q, q)+p(q, g r)] / 2\} \\
& =p(q, g r) .
\end{aligned}
$$

Hence

$$
\psi(p(q, g r)) \leq \psi(p(q, g r))-\phi(p(q, g r))
$$

and $\phi(p(q, g r)) \leq 0$ give $g r=q$, and $r$ is a coincidence point of the pair $(g, T)$. As $g(X) \subseteq$ $S(X)$, there exists a point $u$ in $X$ such that $q=S u$. We claim that $S u=f u$. Using (2.1), we have

$$
\psi(p(f u, g r)) \leq \psi(M(u, r))-\phi(M(u, r))
$$

where

$$
\begin{aligned}
M(u, r) & =\max \{p(S u, T r), p(f u, S u), p(T r, g r),[p(f u, T r)+p(S u, g r)] / 2\} \\
& =\max \{p(S u, S u), p(f u, S u), p(S u, S u),[p(f u, S u)+p(S u, S u)] / 2\} \\
& =p(f u, S u) .
\end{aligned}
$$

Hence

$$
\psi(p(f u, S u)) \leq \psi(p(f u, S u))-\phi(p(f u, S u))
$$

implies that $\phi(p(f u, S u)) \leq 0$. Therefore $f u=S u, u$ is a coincidence point of pair the $(f, S)$. Thus $f u=S u=T r=g r=q$. Now, the weakly compatibility of the pairs $(f, S)$ and $(g, T)$ gives $f q=S q$ and $T q=g q$. From (2.1), we have

$$
\psi(p(f q, q))=\psi(p(f q, g r)) \leq \psi(M(q, r))-\phi(M(q, r))
$$

where

$$
\begin{aligned}
M(q, r) & =\max \{p(S q, \operatorname{Tr}), p(f q, S q), p(\operatorname{Tr}, g r),[p(f q, T r)+p(S q, g r)] / 2\} \\
& =\max \{p(f q, q), p(f q, f q), p(q, q),[p(f q, q)+p(f q, q)] / 2\}=p(f q, q) .
\end{aligned}
$$

From (2.8), we obtain

$$
\psi(p(f q, q)) \leq \psi(p(f q, q))-\phi(p(f q, q))
$$


and so $\phi(p(f q, q)) \leq 0$. Therefore $f q=S q=q$. Similarly, it can be shown that $g q=q$. Therefore $g q=T q=q$. To prove the uniqueness of $q$, suppose that $f p=g p=S p=T p=p$. From (2.1), we have

$$
\psi(p(q, r))=\psi(p(f q, g r)) \leq \psi(M(q, r))-\phi(M(q, r)),
$$

where

$$
\begin{aligned}
M(q, r)= & \max \{p(S q, T r), p(f q, S q), p(T p, g r), \\
& {[p(f q, T r)+p(S q, g r)] / 2\} } \\
= & \max \{p(q, r), p(q, q), p(q, q), \\
& {[p(q, r)+p(q, r)] / 2\}=p(q, r) . }
\end{aligned}
$$

Thus, from (2.10), we obtain

$$
\psi(p(q, r)) \leq \psi(p(q, r))-\phi(p(q, r))
$$

which implies that $\phi(p(q, r)) \leq 0$ and so $q=r$.

Example 2.2 Let $X=\{0,1,2\}$ be a set with partial metric defined by

\begin{tabular}{ll}
\hline$(x, y)$ & $p(x, y)$ \\
\hline$(0,0),(1,1),(2,2)$ & 0 \\
$(0,1),(1,0)$ & 1 \\
$(1,2),(2,1)$ & 2 \\
$(0,2),(2,0)$ & 3 \\
\hline
\end{tabular}

Let $f, g, S, T: X \rightarrow X$ be defined by

\begin{tabular}{lllll}
\hline$x$ & $f(x)$ & $g(x)$ & $S(x)$ & $T(x)$ \\
\hline 0 & 0 & 0 & 0 & 0 \\
1 & 0 & 0 & 2 & 2 \\
2 & 0 & 1 & 1 & 2 \\
\hline
\end{tabular}

Clearly, $f(X) \subseteq T(X)$ and $g(X) \subseteq S(X)$ and the pairs $(f, S)$ and $(g, T)$ are weakly compatible. Also the pair $(f, S)$ satisfies the (E.A)-property; indeed, $x_{n}=0$ for each $n \in \mathbb{N}$ is the required sequence. Note that the pair $(g, T)$ does not commute at 2 . The control functions $\psi, \phi$ : $[0, \infty) \rightarrow[0, \infty)$ are defined by

$$
\psi(t)=3 t \quad \text { and } \quad \phi(t)= \begin{cases}t / 4, & \text { if } t \in[0,4] \\ \frac{e^{-1-}}{2}, & \text { if } t>4\end{cases}
$$

To check the contractive condition (2.1) for all $x, y \in X$, we consider the following cases.

Note that for cases (I) $x=y=0$, (II) $x=0, y=1$, (III) $x=1, y=0$, (IV) $x=1, y=1$, (V) $x=2, y=0$, and (VI) $x=2, y=1$, we have $p(f x, g y)=0$, and hence (2.1) is obviously satisfied. 
(VII) If $x=0, y=2$, then $f x=0, g y=1, S x=0, T y=2$. We have

$$
\begin{aligned}
\psi(p(f x, g y)) & =3 p(0,1)=3 \\
& <\frac{11}{4}(3)=\frac{11}{4} p(0,2) \\
& =\frac{11}{4} p(S x, T y) \leq \frac{11}{4} M(x, y) \\
& =\psi(M(x, y))-\phi(M(x, y)) .
\end{aligned}
$$

(VIII) If $x=1, y=2$, then $f x=0, g y=1, S x=2, T y=2$. We have

$$
\begin{aligned}
\psi(p(f x, g y)) & =3 p(0,1)=3 \\
& <\frac{11}{8}(3+2)=\frac{11}{4}[p(0,2)+p(2,1)] / 2 \\
& =\frac{11}{4}[p(f x, T y)+p(S x, g y)] / 2 \leq \frac{11}{4} M(x, y) \\
& =\psi(M(x, y))-\phi(M(x, y)) .
\end{aligned}
$$

(IX) Now when $x=2, y=2$, then $f x=0, g y=1, S x=1, T y=2$.

$$
\begin{aligned}
\psi(p(f x, g y)) & =3 p(0,1)=3 \\
& <\frac{11}{4}(2)=\frac{11}{4} p(1,2) \\
& =\frac{11}{4} p(S x, T y) \leq \frac{11}{4} M(x, y) \\
& =\psi(M(x, y))-\phi(M(x, y)) .
\end{aligned}
$$

Hence all of the conditions of Theorem 2.1 are satisfied. Moreover, 0 is the unique common fixed point of $f, g, S$ and $T$.

The next example shows that one cannot derive the conclusion of Theorem 2.1 by using a metric induced by a partial metric.

Example 2.3 Let $X=\mathbb{R}^{+}$be a partial metric space with $p(x, y)=\max \{x, y\}$ and $f, g, S, T$ : $X \rightarrow X$ be defined as $f(x)=0, g(x)=\frac{8}{9} x, S x=\frac{3}{2} x$ and $T x=\frac{4}{3} x$. Note that $f(X) \subseteq T(X)$, $g(X) \subseteq S(X)$ with the pair $(f, S)$ satisfies the (E.A)-property. The control functions $\psi, \phi$ : $[0, \infty) \rightarrow[0, \infty)$ are defined by

$$
\psi(t)=4 t \quad \text { and } \quad \phi(t)=\frac{t}{8}
$$

To check the contractive condition (2.1) for all $x, y \in X$, we consider the following cases.

If $x \leq y$, then we have

$$
\begin{aligned}
\psi(p(f x, g y)) & =4\left(\frac{8}{9} y\right) \leq \frac{31}{8}\left(\frac{4}{3} y\right)=\frac{31}{8} p(T y, g y) \\
& \leq \frac{31}{8} M(x, y)=\psi(M(x, y))-\phi(M(x, y))
\end{aligned}
$$


Also, for $x>y$,

$$
\begin{aligned}
\psi(p(f x, g y)) & =4\left(\frac{8}{9} y\right) \\
& \leq \frac{31}{8}\left(\frac{3}{2} x\right)=\frac{31}{8} p(f x, S x) \\
& \leq \frac{31}{8} M(x, y)=\psi(M(x, y))-\phi(M(x, y)) .
\end{aligned}
$$

Hence (2.1) is satisfied for all $x, y \in X$. The pairs $(f, S)$ and $(g, T)$ are weakly compatible and $f, g, S$ and $T$ have a unique common fixed point.

On the other hand, we have $p^{S}(x, y)=|x-y|$. If we take $x=0.5$ and $y=1$, then we have $p^{S}(f x, g y)=\frac{8}{9}, p^{S}(S x, T y)=\frac{7}{12}, p^{S}(f x, S x)=\frac{3}{4}, p^{S}(g y, T y)=\frac{4}{9}$ and $\frac{\left[p^{S}(f x, T y)+p^{S}(S x, g y)\right]}{2}=\frac{53}{72}$. Thus

$$
\begin{aligned}
\psi(p(f x, g y)) & =4\left(\frac{8}{9}\right) \\
& \not \frac{31}{8}\left(\frac{3}{4}\right)=\frac{31}{8} p(f x, S x) \\
& =\frac{31}{8} M(x, y)=\psi(M(x, y))-\phi(M(x, y)) .
\end{aligned}
$$

As any two compatible or noncompatible selfmappings on a partial metric space $X$ satisfy the (E.A)-property, the above result remains true if any one of the pair of mappings is either compatible or noncompatible.

The above theorem is true for any choice of control functions. For example if we take $\psi(t)=t$ and $\phi(t)=(1-\gamma) t$ for $\gamma \in[0,1)$ in Theorem 2.1, we have the following corollary.

Corollary 2.4 Let $X$ be a partial metric space and $f, g, S, T: X \rightarrow X$ be mappings with $f(X) \subseteq T(X)$ and $g(X) \subseteq S(X)$, such that

$$
\begin{gathered}
p(f x, g y) \leq \gamma \max \{p(S x, T y), p(f x, S x), p(T y, g y), \\
[p(f x, T y)+p(S x, g y)] / 2\}
\end{gathered}
$$

holds for all $x, y \in X$, where $\gamma \in[0,1)$. Suppose that one of the pairs $(f, S)$ and $(g, T)$ satisfies the (E.A)-property and one of the subspaces $f(X), g(X), S(X), T(X)$ is closed in $X$. If, for every sequence $\left\{y_{n}\right\}$ in $X$, one of the following conditions holds:

(a) $\left\{g y_{n}\right\}$ is bounded in the case $(f, S)$ satisfies the (E.A)-property,

(b) $\left\{y_{n}\right\}$ is bounded in the case $(g, T)$ satisfies the (E.A)-property,

then the pairs $(f, S)$ and $(g, T)$ have a point of coincidence in $X$. Moreover, if the pairs $(f, S)$ and $(g, T)$ are weakly compatible, then $f, g, S$ and $T$ have a unique common fixed point.

If we take $f=g$ and $S=T$ with $\psi(t)=t$ for all $t \in \mathbb{R}$ in Theorem 2.1, we obtain the following corollary which extends Theorem 3.1 of [32] to a partial metric space.

Corollary 2.5 Let $X$ be a partial metric space and $f, S: X \rightarrow X$ be mappings with $f X \subseteq S X$ such that

$$
p(f x, f y) \leq M(x, y)-\phi(M(x, y))
$$


holds for all $x, y \in X$, where $\phi$ is a control function and

$$
M(x, y)=\max \{p(S x, S y), p(f x, S x), p(S y, f y),[p(f x, S y)+p(S x, f y)] / 2\} .
$$

Suppose that the pair $(f, S)$ satisfies the (E.A)-property and that one of the subspaces $f(X)$, $S(X)$, is closed in $X$. Then the pair $(f, S)$ has a common point of coincidence in $X$. Moreover, if the pair $(f, S)$ is weakly compatible, then $f$ and $S$ have a unique common fixed point.

\section{Well-posedness}

The notion of well-posedness of a fixed point problem has evoked much interest of several mathematicians (see [35-37]).

Definition 3.1 Let $X$ be a partial metric space and $f: X \rightarrow X$ be a mapping. The fixed point problem of $f$ is said to be well-posed if:

(a) $f$ has a unique fixed point $z$ in $X$,

(b) for any sequence $\left\{x_{n}\right\}$ of points in $X$ such that $\lim _{n \rightarrow \infty} p\left(f x_{n}, x_{n}\right)=0$, we have $\lim _{n \rightarrow \infty} p\left(x_{n}, z\right)=0$.

Definition 3.2 Let $X$ be a partial metric space and $\Sigma$ be a set of mappings on $X$. A common fixed point problem $C F(\Sigma)$ is said to be well-posed if:

(a) $z \in X$ is the unique common fixed point of all mappings in $\Sigma$,

(b) for any sequence $\left\{x_{n}\right\}$ of points in $X$, such that $\lim _{n \rightarrow \infty} p\left(f x_{n}, x_{n}\right)=0$ for each $f \in \Sigma$, we have $\lim _{n \rightarrow \infty} p\left(x_{n}, z\right)=0$.

Theorem 3.3 Let $X$ be a partial metric space and $f, g, S, T: X \rightarrow X$ be mappings such that

$$
p(f x, g y) \leq p(S x, T y)-\psi(M(x, y))
$$

holds for all $x, y \in X$, where $\psi$ is a control function and

$$
M(x, y)=\max \{p(S x, T y), p(f x, S x), p(T y, g y),[p(f x, T y)+p(S x, g y)] / 2\} .
$$

Suppose that one of the pairs $(f, S)$ and $(g, T)$ satisfies the (E.A)-property and that one of the subspace $f(X), g(X), S(X), T(X)$ is closed in $X$.If, for every sequence $\left\{y_{n}\right\}$ in $X$, one of the following conditions holds.

(a) $\left\{g y_{n}\right\}$ is bounded in the case $(f, S)$ satisfies the (E.A)-property,

(b) $\left\{f y_{n}\right\}$ is bounded in the case $(g, T)$ satisfies the (E.A)-property.

If the pairs $(f, S)$ and $(g, T)$ are weakly compatible, then $C F(\{f, g, S, T\})$ is well-posed.

Proof From Theorem 2.1 the mappings $f, g, S, T: X \rightarrow X$ have a unique common fixed point (say) $z$ in $X$. Let $\left\{x_{n}\right\}$ be a sequence in $X$ such that

$$
\lim _{n \rightarrow \infty} p\left(f x_{n}, x_{n}\right)=\lim _{n \rightarrow \infty} p\left(g x_{n}, x_{n}\right)=\lim _{n \rightarrow \infty} p\left(S x_{n}, x_{n}\right)=\lim _{n \rightarrow \infty} p\left(T x_{n}, x_{n}\right)=0
$$

Using (3.1) we have

$$
\begin{aligned}
p\left(z, x_{n}\right) & \leq p\left(f z, g x_{n}\right)+p\left(g x_{n}, x_{n}\right)-p\left(g x_{n}, g x_{n}\right) \\
& \leq p\left(S z, T x_{n}\right)-\psi\left(M\left(z, x_{n}\right)\right)+p\left(g x_{n} x_{n}\right)
\end{aligned}
$$




$$
\begin{aligned}
& \leq p\left(z, x_{n}\right)+p\left(x_{n}, T x_{n}\right) \\
& \quad-\psi\left(\left[p\left(f z, T x_{n}\right)+p\left(g x_{n}, S z\right)\right] / 2\right)+p\left(g x_{n}, x_{n}\right),
\end{aligned}
$$

which further implies that

$$
\begin{aligned}
\psi\left(\left[p\left(z, T x_{n}\right)+p\left(x_{n}, z\right)\right] / 2\right) & \leq p\left(x_{n}, T x_{n}\right)+p\left(g x_{n}, x_{n}\right) \\
& \leq 2 p\left(T x_{n}, x_{n}\right)+p\left(g x_{n}, x_{n}\right) .
\end{aligned}
$$

On taking the limit as $n \rightarrow \infty$ we obtain

$$
\lim _{n \rightarrow \infty} \psi\left(\left[p\left(z, T x_{n}\right)+p\left(x_{n}, z\right)\right] / 2\right)=0,
$$

and by the property of $\psi$, we have

$$
\lim _{n \rightarrow \infty} p\left(z, T x_{n}\right)=\lim _{n \rightarrow \infty} p\left(x_{n}, z\right)=0 .
$$

The result then follows.

\section{Competing interests}

The authors declare that they have no competing interests.

\section{Authors' contributions}

All authors contributed equally and significantly in writing this article. All authors read and approved the final manuscript.

\section{Author details}

${ }^{1}$ Department of Mathematics, COMSATS Institute of Information Technology, Abbottabad, 22060, Pakistan. ${ }^{2}$ Department of Mathematics and Computer Sciences, Technical University Eindhoven, Eindhoven, 5612, The Netherlands.

${ }^{3}$ Department of Mathematics and Applied Mathematics, University Pretoria, Lynnwood Road, Pretoria, 0002, South Africa.

${ }^{4}$ Department of Mathematics, Lahore University of Management Sciences, Lahore, 54792, Pakistan.

\section{Acknowledgements}

The authors are grateful to the referees for their careful reading and critical remarks which helped us in improving the presentation of this paper. The authors also thank Pakistan Science Foundation for their support.

\section{Received: 23 August 2013 Accepted: 13 February 2014 Published: 16 June 2014}

\section{References}

1. Abbas, M, Nazir, T, Doric, D: Common fixed point of mappings satisfying (E.A) property in generalized metric spaces. Appl. Math. Comput. 218, 7665-7670 (2012)

2. Aydi, H, Karapınar, E: A Meir-Keeler common type fixed point theorem on partial metric spaces. Fixed Point Theory Appl. 2012, Article ID 26 (2012)

3. Karapınar, E: Generalizations of Caristi Kirk's theorem on partial metric spaces. Fixed Point Theory Appl. 2011, Article ID 4 (2011)

4. Karapınar, E, Yuce, IS: Fixed point theory for cyclic generalized weak contraction on partial metric spaces. Abstr. Appl. Anal. 2012, Article ID 491542 (2012)

5. Karapınar, E, Shobkolaei, N, Sedghi, S, Vaezpour, SM: A common fixed point theorem for cyclic operators on partial metric spaces. Filomat 26(2), 407-414 (2012)

6. Latif, A, Al-Mezel, SA: Fixed point results in quasi metric spaces. Fixed Point Theory Appl. 2011, Article ID 178306 (2011)

7. Matthews, SG: Partial metric topology. In: Proc. 8th Summer Conference on General Topology and Applications. Ann. New York Acad. Sci., vol. 728, pp. 183-197 (1994)

8. Matthews, SG: The topology of partial metric spaces. Research report RR 222. University of Warwick (1992)

9. Abdeljawad, T, Aydi, H, Karapınar, E: Coupled fixed points for Meir-Keeler contractions in ordered partial metric spaces. Math. Probl. Eng. 2012, Article ID 327273 (2012)

10. Aydi, H: Some fixed point results in ordered partial metric spaces. arXiv:1103.3680v1 [math.GN] (2011)

11. Aydi, H, Karapınar, E: New Meir-Keeler type tripled fixed point theorems on ordered partial metric spaces. Math. Probl. Eng. 2012, Article ID 409872 (2012)

12. Aydi, H, Amor, SH, Karapınar, E: Berinde-type generalized contractions on partial metric spaces. Abstr. Appl. Anal. 2013, Article ID 312479 (2013) 
13. Bukatin, M, Shorina, SY: Partial metrics and co-continuous valuations. In: Nivat, M et al. (eds.) Foundations of Software Science and Computation Structure. Lecture Notes in Computer Science, vol. 1378, pp. 125-139 Springer, Berlin (1998)

14. Bukatin, M, Kopperman, R, Matthews, S, Pajoohesh, H: Partial metric spaces. Am. Math. Mon. 116, 708-718 (2009)

15. Oltra, S, Valero, O: Banach's fixed theorem for partial metric spaces. Rend. Ist. Mat. Univ. Trieste 36, 17-26 (2004)

16. Romaguera, S: A Kirk type characterization of completeness for partial metric spaces. Fixed Point Theory Appl. 2010, Article ID 493298 (2010)

17. Schellekens, MP: The correspondence between partial metrics and semivaluations. Theor. Comput. Sci. 315, 135-149 (2004)

18. Valero, O: On Banach fixed point theorems for partial metric spaces. Appl. Gen. Topol. 6, 229-240 (2005)

19. Karapınar, K: A note on common fixed point theorems in partial metric spaces. Miskolc Math. Notes 12(2), 185-191 (2011)

20. Haghi, RH, Rezapour, S, Shahzad, N: Be careful on partial metric fixed point results. Topol. Appl. 160(3), 450-454 (2013)

21. Jleli, M, Karapınar, K, Samet, B: Further remarks on fixed point theorems in the context of partial metric spaces. Abstr. Appl. Anal. 2013, Article ID 715456 (2013)

22. Samet, B, Vetro, C, Vetro, F: From metric spaces to partial metric spaces. Fixed Point Theory Appl. 2013, Article ID 5 (2013)

23. Nashine, HK, Kadelburg, Z: Cyclic contractions and fixed point results via control functions on partial metric spaces. Int. J. Anal. 2013, Article ID 726387 (2013)

24. Nashine, HK, Kadelburg, Z: Fixed point theorems via various cyclic contractive conditions in partial metric spaces. Publ. Inst. Math. (Belgr.) 93(107), 69-93 (2013)

25. Altun, I, Erduran, A: Fixed point theorems for monotone mappings on partial metric spaces. Fixed Point Theory Appl. 2011, Article ID 508730 (2011)

26. Abbas, M, Nazir, T: Fixed point of generalized weakly contractive mappings in ordered partial metric spaces. Fixed Point Theory Appl. 2012, Article ID 1 (2012)

27. Abbas, M, Nazir, T, Romaguera, S: Fixed point results for generalized cyclic contraction mappings in partial metric spaces. Rev. R. Acad. Cienc. Exactas Fís. Nat., Ser. A Mat. 106(2), 287-297 (2012)

28. Karapınar, E, Rakocevic, V: On cyclic generalized weakly C-contractions on partial metric spaces. J. Appl. Math. 2013, Article ID 831491 (2013)

29. Jungck, G: Compatible mappings and common fixed points. Int. J. Math. Math. Sci. 9(4), 771-779 (1986)

30. Sessa, S: On a weak commutativity condition of mappings in fixed point considerations. Publ. Inst. Math. (Belgr.) 32 , 149-153 (1982)

31. Aamri, A, Moutawakil, DE: Some new common fixed point theorems under strict contractive conditions. J. Math. Anal. Appl. 270, 181-188 (2002)

32. Babu, GVR, Negas, AG: A common fixed point theorem for weakly compatible mappings. Appl. Math. E-Notes 10 167-174 (2010)

33. Beg, I, Abbas, M: Coincidence and common fixed points of noncompatible maps. J. Appl. Math. Inform. 29(3-4), 743-752 (2011)

34. Cho, SH, Bae, JS: Common fixed point theorems for mappings satisfying property (E.A) on cone metric spaces. Math. Comput. Model. 53, 945-951 (2011)

35. Lahiri, BK, Das, P: Well-posedness and porosity of certain classes of operators. Demonstr. Math. 38, 170-176 (2005)

36. Popa, V: Well-posedness of fixed point problem in orbitally complete metric spaces. Stud. Cercet. Științ. - Univ. Bacău, Ser. Mat. 16, suppl., 209-214 (2006). Proceedings of ICMI 45, Bacau, September 18-20, 2006

37. Reich, S, Zaslavski, AJ: Well-posedness of fixed point problems. Far East J. Math. Sci. Special Volume, part III, 393-401 (2001)

\section{Submit your manuscript to a SpringerOpen ${ }^{\circ}$ journal and benefit from:}

- Convenient online submission

Rigorous peer review

- Immediate publication on acceptance

- Open access: articles freely available online

- High visibility within the field

- Retaining the copyright to your article 